\title{
Photosensitizer Adhered to Cell Culture Microplates Induces Phototoxicity in Carcinoma Cells
}

\author{
Verena Ziegler, ${ }^{1,2}$ Tobias Kiesslich, ${ }^{3,4}$ Barbara Krammer, ${ }^{2}$ and Kristjan Plaetzer1 \\ ${ }^{1}$ Laboratory of Photodynamic Inactivation of Microorganisms, Department of Materials Science and Physics, University of Salzburg, \\ Hellbrunnerstraße 34, 5020 Salzburg, Austria \\ ${ }^{2}$ Department of Molecular Biology, University of Salzburg, Hellbrunnerstraße 34, 5020 Salzburg, Austria \\ ${ }^{3}$ Department of Internal Medicine I, Paracelsus Medical University and Salzburger Landeskliniken (SALK), Muellner Hauptstrasse 48, \\ 5020 Salzburg, Austria \\ ${ }^{4}$ Institute of Pathology, Paracelsus Medical University and Salzburger Landeskliniken (SALK), Muellner Hauptstrasse 48, \\ 5020 Salzburg, Austria
}

Correspondence should be addressed to Kristjan Plaetzer; kristjan.plaetzer@sbg.ac.at

Received 3 September 2012; Accepted 9 October 2012

Academic Editor: Tim Maisch

Copyright (C) 2013 Verena Ziegler et al. This is an open access article distributed under the Creative Commons Attribution License, which permits unrestricted use, distribution, and reproduction in any medium, provided the original work is properly cited.

\begin{abstract}
In vitro experiments in plastic receptacles are the basis of characterization of new photosensitizers (PSs) for the photodynamic therapy. We recently reported that lipophilic PSs adhere to cell culture microplates in a kinetic-like manner (Engelhardt et al., 2011). In the current study, we examined the interaction and phototoxic effects of the microplate-adhered PS in cancer cells. Therefore, we preloaded microplates with hypericin, Foscan, PVP-hypericin, or aluminum (III) phthalocyanine tetrasulfonate chloride $\left(\right.$ AlPCS $\left._{4}\right)$ for 24 hours and measured the PS distribution after addition of A431 human carcinoma cells: following another 24 hours up to $68 \%$ of hypericin were detected in the cell fraction. The hydrophilic PVP-hypericin and AlPCS 4 also diffused into the cells, but the quantities of PS adherence were considerably lower. Microplate-adhered Foscan appeared not to be redistributed. In contrast to the hydrophilic PSs, the cellular phototoxicity of microplate-adhered lipophilic PS was high, independent of whether the PS (i) was pre-loaded onto microplates or (ii) added simultaneously with the cells or (iii) one day after cell seeding. Based on these results, we suggest testing lipophilic PS dyes for their adherence to microplates. Furthermore, the ability of plastic materials to (reversibly) store PSs might represent a new approach for the PS delivery or the development of antimicrobial coatings.
\end{abstract}

\section{Introduction}

In the past decades several photodynamic approaches based on a photosensitizing agent and its interaction with visible light have gained attention. The most prominent and successful one is photodynamic therapy (PDT), a well-established treatment for the eradication of neoplastic cells (for review see $[1-3])$. Up to date, approvals for the application of several photosensitizers against malignant and nonmalignant indications exist in Europe, the US, Canada, and Japan [4]. Also, photodynamic inactivation of microorganisms (PDI) has become very important due to the fact that even antibiotic-resistant bacteria are susceptible to this treatment $[5,6]$ and that natural substances may be employed as photoantibiotics [7]. Both PDT and PDI are based on the (semi-)selective uptake of a photosensitizing agent, the photosensitizer (PS), into the target tissue or cells and subsequent illumination with visible light. This results in the generation of reactive oxygen species (ROS) - most importantly singlet oxygen-thereby eradicating target cells without harming healthy tissue [4].

Cell-based in vitro experiments are a key tool not only in PDT/PDI research but generally for the development and improvement of anticancer or antimicrobial drugs. Such cell culture studies offer several advantages such as costefficiency, high throughput (compared to animal testing), no ethical objections, and an extraordinary flexibility. However, the limitations of cell culture experiments include most 
importantly the limited transferability of in vitro testing to the in vivo situation. Also PDT/PDI research frequently struggles with this constriction, in particular regarding the dosimetry of PSs and incubation parameters.

As PDT and PDI are a multiparametrical procedures-especially with newly synthesized or discovered PSs-in vitro testing in the standard (96-well) microplate format (MP) is routinely performed to screen for typical parameters such as cellular uptake kinetics, duration, and intensity of illumination, PS concentration, and incubation times. Plastic microplates are widely used in these initial experiments due to the convenient handling and the possibility of multiparametric analyses. Nevertheless, the plastic material, usually polystyrenes or polypropylenes, may interact with the molecules of interest and influence biological processes and results.

In a previous study we demonstrated the adherence of PSs to the surface of plastic microplates and systematically analyzed the resulting background fluorescence and its influence on measurement results regarding cellular PS uptake data. We identified differences between PSs with different physiochemical properties, but also between microplates of different manufacturers and illustrated the need of controls to correct for fluorescence caused by adhering PS [8].

1.1. Photosensitizers. In this study we focus on the cytotoxic effects of plate-adhered PS in photodynamic experiments. Four well-established PSs with different physicochemical properties such as lipophilicity were used to investigate the uptake of plate-adhered PS into cells and its phototoxic effect upon illumination. In continuance to our previous report [8] A431 human epidermoid carcinoma cells serve as a model cell line, due to their frequent use and wide distribution, including PDT-related research and their advanced characterization (e.g., see [9-11]). PSs were selected in order to represent a wide spectrum of available PSs and based on our findings by Engelhardt et al. [8]. Foscan is a clinically approved and widespread bacteriochlorin with a strong lipophilic character; hypericin represents a group of naturally occurring PSs, offering a high fluorescence quantum yield and reduced photobleaching [12]. Including polyvinylpyrrolidone- (PVP-) hypericin allows for the direct comparison between the hydrophobic PS hypericin and a water-soluble formulation of this compound. The phthalocyanine $\mathrm{AlPCS}_{4}$ (aluminum (III) phthalocyanine tetrasulfonate chloride) was tested to represent a group of strongly hydrophilic PSs. As a result of the high adherence of lipophilic PSs to Costar MPs [8] we used these plates for all the experiments. Furthermore, we compared the resulting phototoxicity to standard PDT protocols and examined the influence of plate-adhered PS on cells without illumination (dark toxicity). Besides demonstrating the significant photodynamic effect of plate-adhered PS, this study might open the door towards a new method of in vitro photosensitizer drug delivery in PDT, employing the property of certain PSs to adhere to nonpolar surfaces and therefore enabling localized long-term incubation provided by adhered PS.

\section{Materials and Methods}

2.1. Microplates. To analyze the distribution and uptake of the adherent PS into cells, 96-well clear flat bottom polystyrene plates obtained from Costar (catalog number 3598, Corning B.V. Life Sciences, Amsterdam, The Netherlands) were used. Phototoxicity of PS that adheres to microplates was investigated using 96-well plates with black walls and clear bottom (Costar, catalog number 3603).

Foscan (meso-tetrahydroxyphenyl chlorine, mTHPC, temoporfin) was obtained from Biolitec AG (Jena, Germany). The stock solution of Foscan was used as provided by the manufacturer (i.e., dissolved in ethanol-propylene at a stock concentration of $5.87 \mathrm{mM}$ ). Hypericin was provided by Planta Natural Products (Vienna, Austria) and dissolved in dimethyl sulfoxide (DMSO) at $1.98 \mathrm{mM}$ for the stock solution. Hypericin bound to polyvinylpyrrolidone (PVPhypericin) was synthesized as described by Kubin et al. [13] to establish water solubility. Stock solutions of PVP-hypericin were prepared in DPBS $(200 \mu \mathrm{M}$; Dulbecco's phosphatebuffered saline). AlPCS 4 was obtained from Porphyrin Products (Logan, USA). For stock solutions, $\mathrm{AlPCS}_{4}$ was prepared in DPBS (1.0 mM).

All PS working solutions were prepared in cell culture medium without serum and all working steps that involved PS were performed under subdued light conditions. Table 1 summarizes the PS concentrations and the detailed parameters for fluorescence measurement of each PS.

2.2. Cell Culture. A431 human epidermoid carcinoma cells (ATCC-Nr. CRL-1555) were cultured in Dulbecco's modified Eagle's medium (DMEM) supplemented with $10 \mathrm{mM}$ HEPES, 5\% (v/v) fetal bovine serum (FBS), $2 \mathrm{mM} \mathrm{L-}$ glutamine, $1 \mathrm{mM}$ Na-pyruvate, $100 \mathrm{U} \mathrm{mL}^{-1}$ penicillin, and $0.1 \mathrm{mg} \mathrm{mL}^{-1}$ streptomycin. All media and supplements were obtained from PAA (Pasching, Austria). Cells were grown at $37^{\circ} \mathrm{C}$ and $5 \% \mathrm{CO}_{2}$ in a humidified atmosphere; all experiments were done using cells of passage number 5 to 23 .

\subsection{PS Redistribution of Microplate-Adhered PS after Addition} of Cells. To analyze the amount of PS that is taken up by cells after the microplate was loaded with PS, we measured PS fluorescence of cells separately from the microplate after incubation with cells (experimental scheme shown in Figure 1(a)). Therefore, the dye was diluted in DMEM without serum to the working concentrations, $100 \mu \mathrm{L}$ of medium with PS was put into a microplate and incubated for $24 \mathrm{~h}$ at $37^{\circ} \mathrm{C}$. The microplate was then washed twice with DPBS and 0 , $1 \cdot 10^{4}, 2 \cdot 10^{4}$ or $4 \cdot 10^{4}$ cells in medium without serum were added to each well. After incubation for $24 \mathrm{~h}$, the medium was removed and cells were trypsinized from the microplate and transferred into a new microplate. To both microplates, the original one ("MP2") and the one the cells were transferred into ("MP3"), $100 \mu \mathrm{L} 1 \%$ Triton-X 100 in DPBS was added for cell lysis $10 \mathrm{~min}$ prior to fluorescence intensity measurement. Additionally, in a control plate, cells were directly lyzed in the incubation plate without trypsinization ("MP1"). 


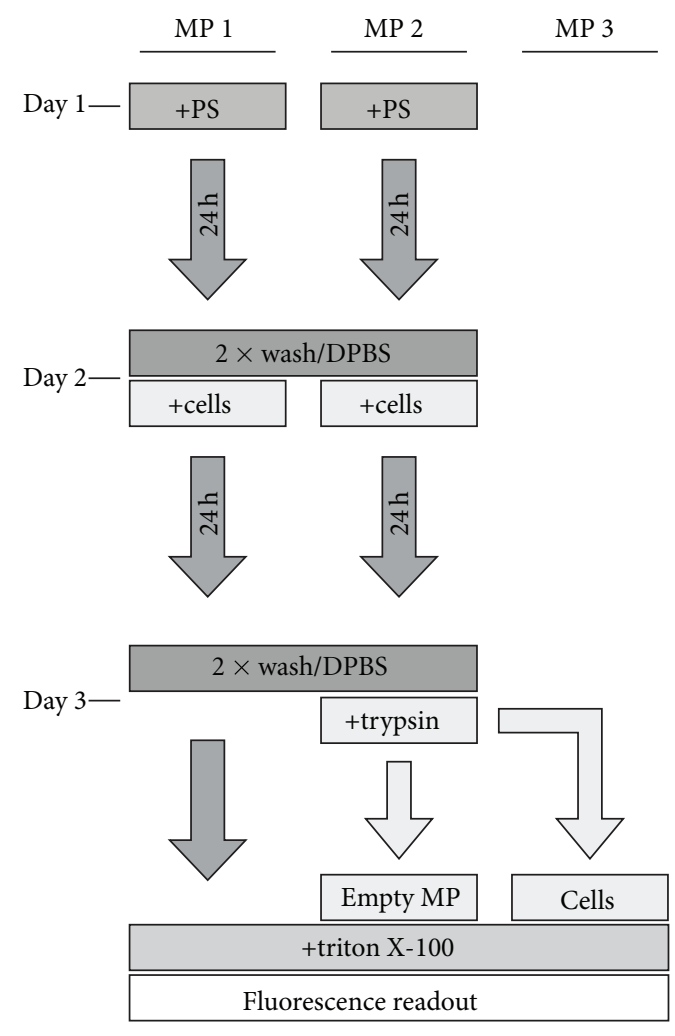

(a)
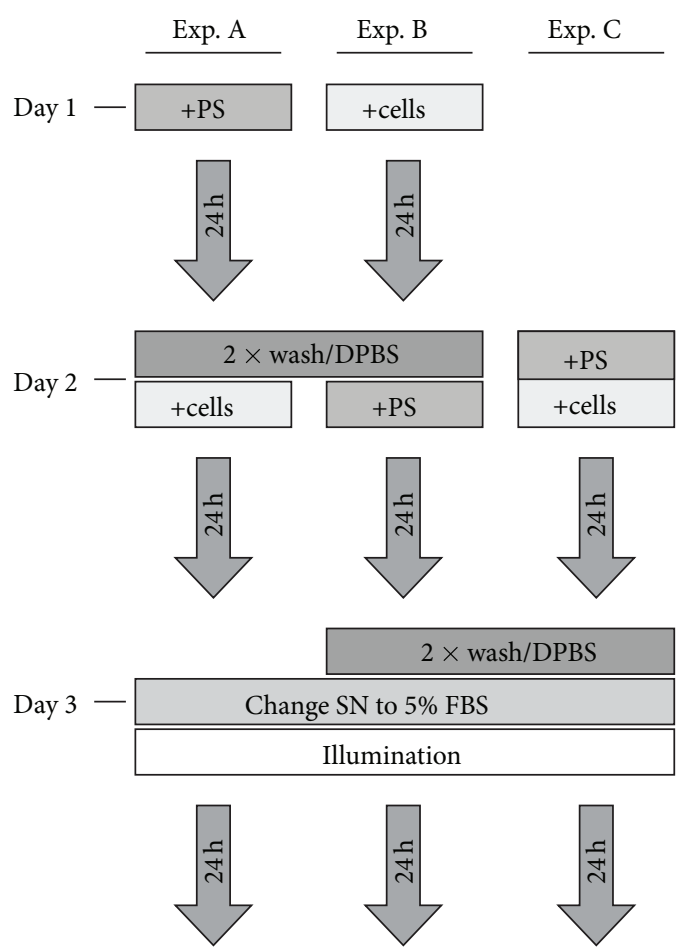

Day $4-$

(b)

Figure 1: Experimental schemes. (a) The distribution of PS from microplates that were preincubated with PSs and then incubated with A431 cells was analyzed in three microplates (MP 1, MP 2, and MP 3). (b) Different incubation protocols were applied prior to photodynamic treatment to assess the phototoxicity of microplate-adhered PS. Abbreviations: DPBS: Dulbecco's phosphate-buffered saline; FBS: fetal bovine serum; MP: microplate; PS: photosensitizer; SN: supernatant.

TABlE 1: Photosensitizer concentrations, fluorescence measurement parameters, and physicochemical characteristics.

\begin{tabular}{lccccc}
\hline Photosensitizer & Concentrations $(\mu \mathrm{M})$ & Excitation wavelength $(\mathrm{nm})$ & Emission wavelength $(\mathrm{nm})$ & $\left.\mathrm{MW}_{(\mathrm{g} \mathrm{mol}}{ }^{-1}\right)$ & Lipophilicity $^{-}$ \\
\hline Hypericin & $1.0,5.0$ & 340 & 604 & 504 & +++ \\
PVP-Hypericin & $1.0,5.0$ & 340 & 604 & $504^{\mathrm{a}}$ & -- \\
Foscan & $0.4,2.0$ & 426 & 658 & 680 & +++ \\
AlPCS $_{4}$ & $10.0,50.0$ & 410 & 684 & 895 & --- \\
\hline
\end{tabular}

Molecular weight of the photoactive compound hypericin.

Fluorescence intensity was thereafter read using an Infinite M200 Pro microplate reader (Tecan, Groedig, Austria).

2.4. Phototoxicity of PS Adhered to Microplates. To assess the phototoxic effect of PS that is attached to microplates, we performed phototoxicity experiments with three different PS incubation protocols referred to as "Exp. A, B, and C" as illustrated in Figure 1(b).

Exp. A. Microplates were incubated with PS in $100 \mu \mathrm{L}$ of medium without serum for $24 \mathrm{~h}$ at $37^{\circ} \mathrm{C}$. Afterwards, plates were washed twice with $100 \mu \mathrm{L}$ DPBS and $1 \cdot 10^{4}$ cells were seeded into each well in medium without FBS. After another $24 \mathrm{~h}$ incubation, the medium was replaced by culture medium with $5 \%$ serum and cells were illuminated, according to the illumination parameters given in Table 2 .
Exp. B. Ten-thousand cells were seeded into a microplate in medium without FBS. After $24 \mathrm{~h}$ incubation, the medium was changed to medium with PS and plates were again incubated for $24 \mathrm{~h}$. Thereafter, cells were washed twice and culture medium with $5 \%$ serum was added before illumination.

Exp. C. Ten-thousand cells were seeded into microplates in medium without serum but with PS at the appropriate working concentration. Plates were incubated for $24 \mathrm{~h}$ and washed twice with $100 \mu \mathrm{L}$ DPBS and medium with 5\% FBS was put into each well prior to illumination.

The cells were illuminated from below the cell culture receptacles using diode arrays described in Pieslinger et al. [14], with wavelengths appropriate for the according PS. After illumination, all microplates were processed identically: $24 \mathrm{~h}$ after illumination cellular survival was assessed by means of reduction of blue resazurin (Sigma Aldrich, Vienna, Austria), 
TABLE 2: Illumination parameters for photodynamic treatment.

\begin{tabular}{lccc}
\hline Photosensitizer & $\begin{array}{c}\text { Illumination wavelength } \\
(\mathrm{nm})\end{array}$ & $\begin{array}{c}\text { Light intensity } \\
\left(\mathrm{mW} \cdot \mathrm{cm}^{-2}\right)\end{array}$ & $\begin{array}{c}\text { Light fluence } \\
\left(\mathrm{J} \cdot \mathrm{cm}^{-2}\right)\end{array}$ \\
\hline Hypericin & $610 \pm 10$ & 2.33 & $0.0-2.1$ \\
PVP-Hypericin & $610 \pm 10$ & 2.33 & $0.0-2.1$ \\
Foscan & $660 \pm 10$ & 2.33 & $0.0-2.1$ \\
AlPCS $_{4}$ & $660 \pm 10$ & 6.74 & $0.0-6.1$ \\
\hline
\end{tabular}

to resorufin, yielding pink fluorescence. This reaction is most probably catalyzed by diaphorases in living cells [15]. For this purpose, $20 \mu \mathrm{L}$ of resazurin $(2.5 \mathrm{mM}$ in DPBS $)$ were added to each well and incubated for $2 \mathrm{~h}$. The resulting fluorescence signal was measured at $\lambda_{\mathrm{ex}}=535 \mathrm{~nm} / \lambda_{\mathrm{em}}=588 \mathrm{~nm}$ using the Infinite M200Pro microplate reader.

Based on these results, the LD50 values were calculated from the curves by interpolation. The LD50 values represent the light dose which induces $50 \%$ lethality of cells.

2.5. Toxicity without Illumination. To investigate the dark toxic effects of the dye, that is, without illumination, towards cells treated with a standard PDT protocol and cells seeded into preincubated plates, the viability of cells without illumination was analyzed (according to incubation protocols $\mathrm{A}$ and $\mathrm{B}$, described above). The effects of PS incubation where then assessed by comparing cell viability to that of untreated controls.

2.6. Data Processing and Statistics. Mean values from microplate replicates were corrected for blank values (wells treated as described but without cells and PS). All data represent mean values of at least three independent experiments \pm SEM.

\section{Results}

3.1. PS Redistribution of Microplate-Adhered PS after Addition of Cells. In order to determine a redistribution of PS adhered to empty microplates into eukaryotic cells after their addition, we performed PS uptake experiments to analyze the distribution of PS in cells and plates.

For means of comparison of the basal adherence of different PSs to MPs, we calculated the ratio of the signal of wells without cells (and preloaded with PS) to blanks (no cells, no PS; see Table 3). As the blanks are supposed to exhibit a stable base fluorescence signal, this ratio is intended to show the differences in signal intensity for all PSs independent from diverging measurement parameters for the different PSs. This ratio shows that, for $1.0 \mu \mathrm{M}$ hypericin, the total fluorescence is 5.30-fold higher in controls w/o cells compared to blanks; for $5.0 \mu \mathrm{M}$ hypericin, the signal intensity ratio almost doubled to a factor of 9.26. Furthermore, for all PSs analyzed a 5-fold increase in PS concentration does not result in an equally increased fluorescence level in the controls, but only in an elevation in between a factor of 1.43 and 1.86 compared to the lower PS concentration.
TABLE 3: Fluorescence intensity of wells preloaded with PS (without cells) relative to blank wells.

\begin{tabular}{lcc}
\hline \multicolumn{2}{c}{ Photosensitizer } & Ratio (preloaded wells)/(blank) \\
\hline \multirow{2}{*}{ Hypericin } & $1.0 \mu \mathrm{M}$ & 5.30 \\
& $5.0 \mu \mathrm{M}$ & 9.26 \\
\hline \multirow{2}{*}{ PVP-hypericin } & $1.0 \mu \mathrm{M}$ & 1.94 \\
& $5.0 \mu \mathrm{M}$ & 2.77 \\
\hline \multirow{2}{*}{ Foscan } & $0.4 \mu \mathrm{M}$ & 618.62 \\
& $2.0 \mu \mathrm{M}$ & 1148.54 \\
\hline \multirow{2}{*}{ AlPCS $_{4}$} & $10 \mu \mathrm{M}$ & 1.10 \\
& $50 \mu \mathrm{M}$ & 1.79 \\
\hline
\end{tabular}

Under cell-free conditions and for all PSs and concentrations employed, no significant percentage of PS was detached from the plastic material, as no fluorescence was detected in the according control wells of the new MP ("MP3," Figure 2). After incubating the MPs for $24 \mathrm{~h}$ with $1 \mu \mathrm{M}$ hypericin (Figure $2(\mathrm{a})$ ) or $5 \mu \mathrm{M}$ hypericin (Figure $2(\mathrm{~b})$ ), the highest concentration of the lipophilic hypericin was found in samples where no cells have been added. If cells were added after $24 \mathrm{~h}$ PS incubation, for both hypericin concentrations, the total amount of PS decreased ("MP1"). Compared to wells without cells, constantly around $40 \%$ of hypericin remained adhered to the MP after removal of the cells by trypsinization ("MP2"). When analyzing these separately measured cells ("MP3"), we found that $37 \%-67 \%$ of hypericin has been taken up by cells; the total amount of cell-bound hypericin increases with increasing cell numbers per well.

For MPs that were preincubated with the water-soluble PVP-hypericin (Figures 2(c) and 2(d)) in samples with 10000 or 20000 cells up to $30 \%$ of the PS was lost if cells were lysed directly in the plate ("MP1"). Again about $40 \%$ of the remaining PS adheres to the MP ("MP2"), whereas, for the lower concentration of $1.0 \mu \mathrm{M}$, a slightly lower rate was internalized into the cells and detected in the separate MP ("MP3"). For 5.0 $\mu \mathrm{M}$ PVP-hypericin, even a higher amount of up to $55.6 \%$ of the PS was found to be moved to the new microplate with the cells. Taking into account the control/blank ratio (Table 3), we can also see that, compared to pure hypericin, in total by far less PVP-hypericin adheres to the MP after $24 \mathrm{~h}$ incubation. The fluorescence in the control is only 1.94-fold higher than the blank for $1 \mu \mathrm{M}$ PVPhypericin and 2.77 -fold higher for $5 \mu \mathrm{M}$, respectively.

After incubation of microplates with $0.4 \mu \mathrm{M}$ (Figure 2(e)) or $2.0 \mu \mathrm{M}$ (Figure 2(f)) of the lipophilic PS Foscan, $29 \%-61 \%$ of the PS are lost by addition of cells ("MP1"); 


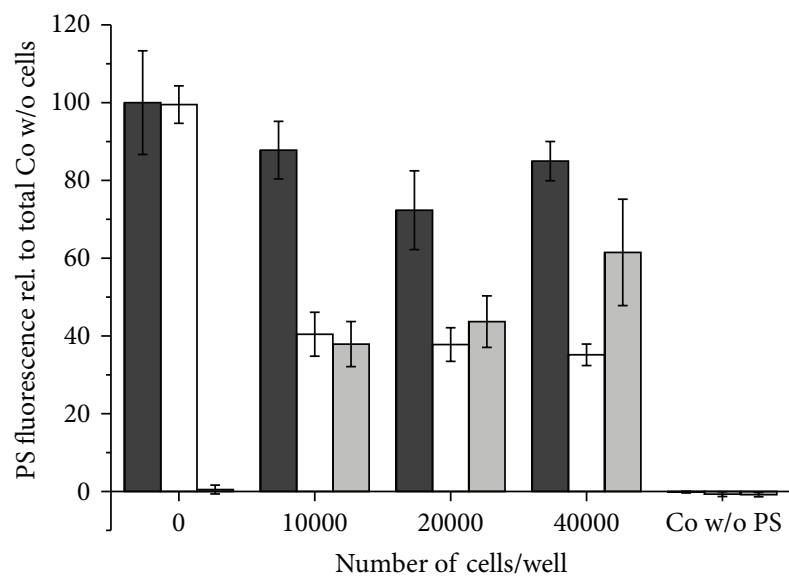

$\square$ MP1: sum signal $\square$ MP3: cell-bound PS MP2: MP-adhered PS

(a)

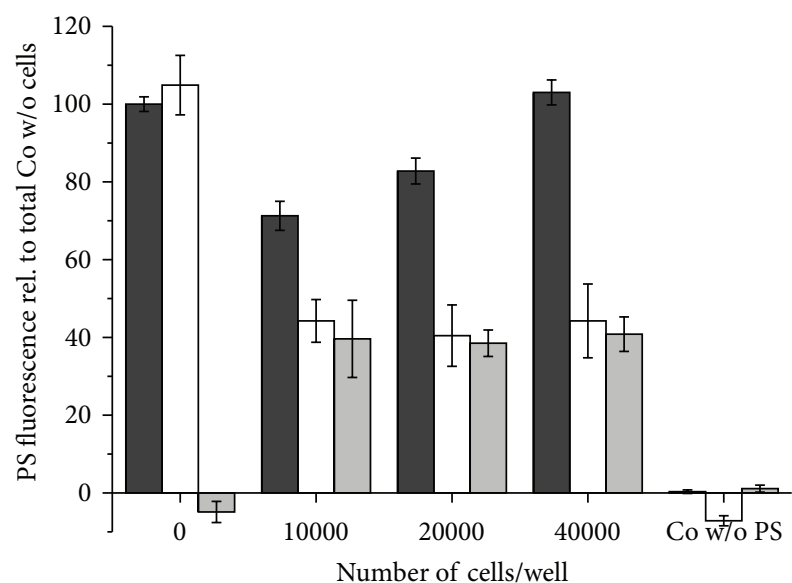

$\square$ MP1: sum signal $\square$ MP3: cell-bound PS MP2: MP-adhered PS

(c)

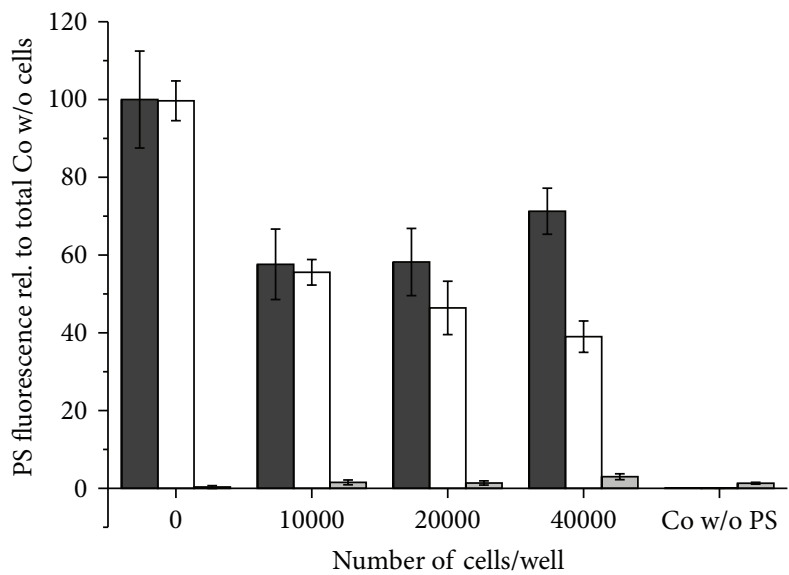

MP1: sum signal MP2: MP-adhered PS

(e)

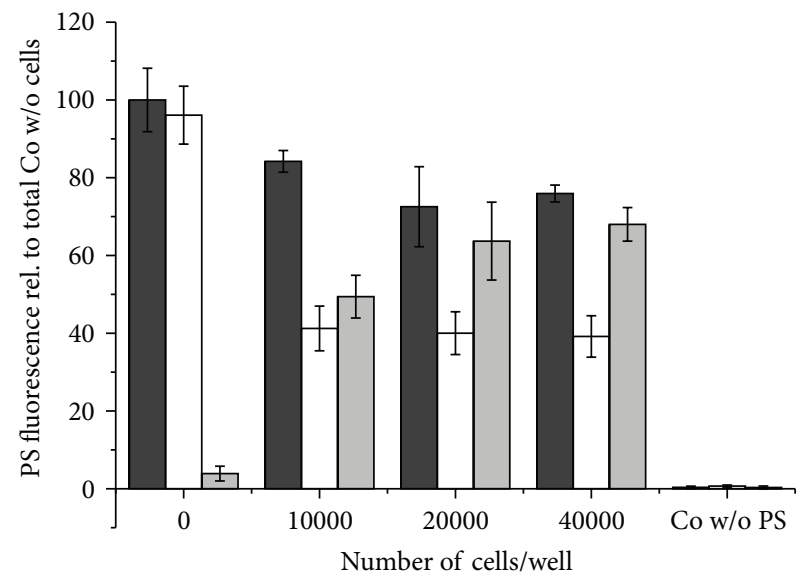

$\square$ MP1: sum signal MP2: MP-adhered PS

(b)

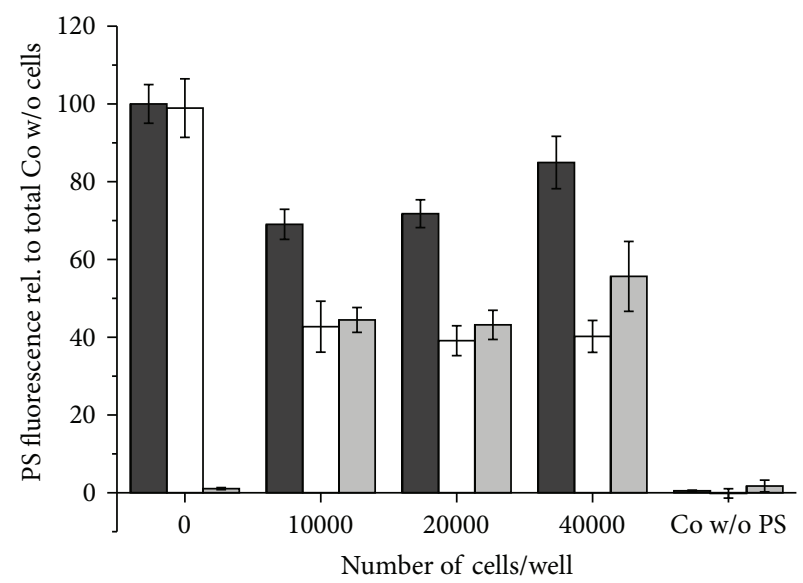

MP1: sum signal MP2: MP-adhered PS

(d)

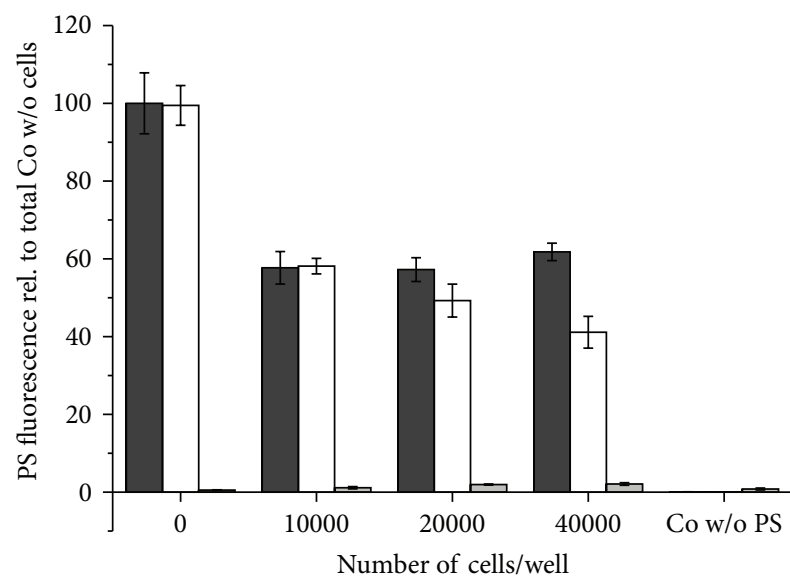

MP1: sum signal MP2: MP-adhered PS

(f)

FIgUre 2: Continued. 


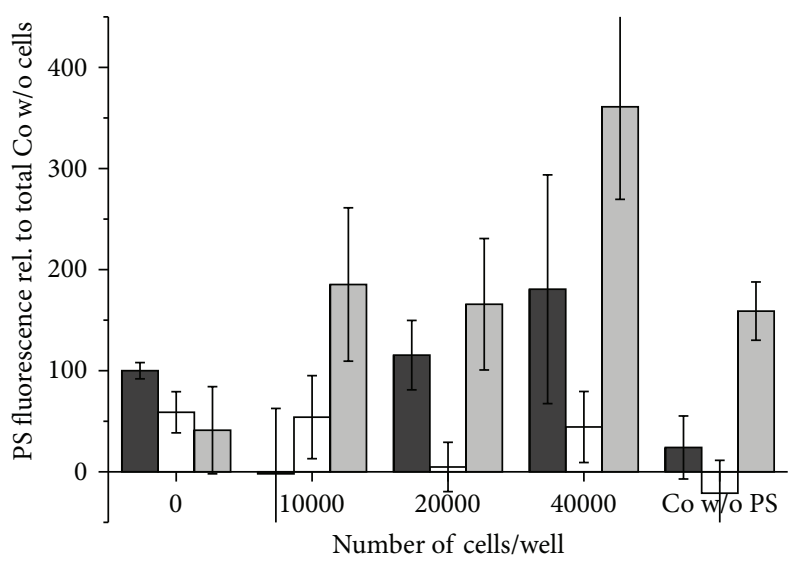

$\square$ MP1: sum signal
$\square$ MP2: MP-adhered PS

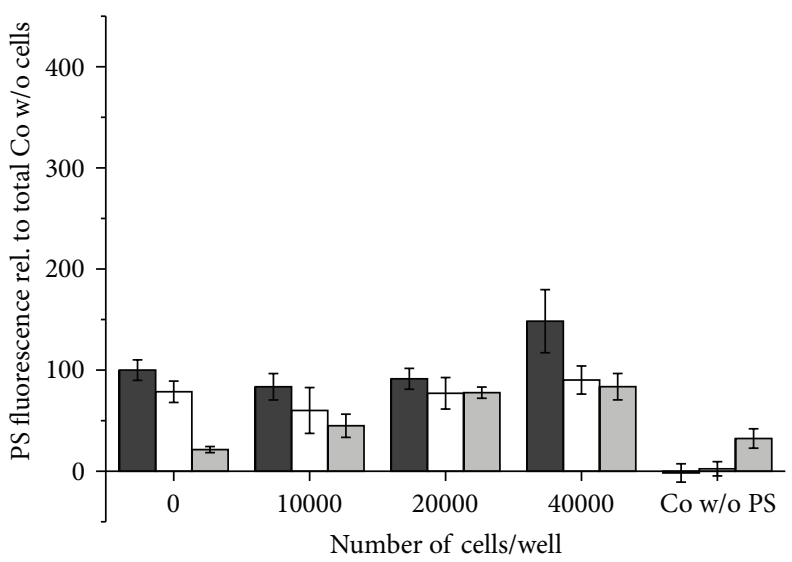

MP1: sum signal MP2: MP-adhered PS

(g)

(h)

FIGURE 2: Distribution of microplate-adhered PS after addition of cells. The distribution of PS from microplates was determined by plates that were preincubated with $1.0 \mu \mathrm{M}$ hypericin (a) or $5.0 \mu \mathrm{M}$ hypericin (b); $1.0 \mu \mathrm{M}$ PVP-hypericin (c) or $5.0 \mu \mathrm{M}$ PVP-hypericin (d); $0.4 \mu \mathrm{M}$ Foscan (e) or $2.0 \mu \mathrm{M}$ Foscan (f) or $10 \mu \mathrm{M} \mathrm{AlPCS}_{4}$ (g) and $50 \mu \mathrm{M} \mathrm{AlPCS}_{4}$ (h). The amount of PS was assessed directly in the incubation plate (MP1) or cells were transferred from the incubation microplate to a new microplate to analyze the PS remaining adhered to the plate (MP2) or having been bound to cells (MP3). Parameters for fluorescence intensity measurements are listed in Table 2. Results are displayed relative to controls preincubated with PS but without cells. Abbreviations: MP: microplate; PS: photosensitizer.

the remaining PS is almost completely adhered to the MP ("MP2"). Only a small amount of PS, not exceeding 3\% of fluorescence measured in PS-control wells, is found to be transferred to the new plate together with the cells ("MP3"). These values are stable and seem independent from the cell number and Foscan concentration, although we observe a slight trend of decreasing rates of plate-adhered PS with increasing cell numbers per well. In total, the amount of plateadhered PS is extremely high for this PS, as the fluorescence in the controls w/o cells is 618.62-times higher than in the blanks after $24 \mathrm{~h}$ incubation with $0.4 \mu \mathrm{M}$ and elevated even by a factor of 1148.54 after incubating with $2.0 \mu \mathrm{M}$ Foscan.

For hydrophilic AlPCS 4 these ratios are different; the controls incubated with $\mathrm{AlPCS}_{4}$ exhibit only 1.10-fold the fluorescence of the blanks for $10 \mu \mathrm{M}$ and 1.79 -fold for $50 \mu \mathrm{M}$, respectively. This indicates that only very small amounts of $\mathrm{AlPCS}_{4}$ adhere to the MPs. For the concentration of $10 \mu \mathrm{M}$ (Figure $2(\mathrm{~g})$ ) it is difficult to identify clear trends due to the high experimental error caused by the low signal intensity. However, $10 \mu \mathrm{M} \mathrm{AlPCS}$ is the only setup showing a higher fluorescence in wells containing cells than wells without cells. If cells were lysed directly in the wells preincubated with $\mathrm{AlPCS}_{4}$, the fluorescence of samples with 20000 or 40000 cells ("MP1") is $115 \%$ and $180 \%$, respectively, of controls without cells; and the effect is even more pronounced if cells were trypsinized and analyzed separately from the original MP, showing $165 \%$ to $361 \%$ fluorescence, compared to the control. For $50 \mu \mathrm{M} \mathrm{AlPCS}$ (Figure 2(h)), once more only little amounts of PS adhere to the MP after $24 \mathrm{~h}$ incubation ("MP1"); therefore also the quantity of PS that is available for cells is limited. Only in this experimental setup the fluorescence of $\mathrm{AlPCS}_{4}$ is higher in samples with cells directly lysed in the plate than in samples without cells. In case cells are removed from the MP loaded with PS, approximately a half of the sensitizer is relocated to the second plate; the same amount is left in the original MP.

3.2. Phototoxicity of PS Adhered to Microplates. The effect of plate-adhered PSs on cell viability after photodynamic treatment was investigated and compared to the established in vitro PDT protocol and to a protocol with the PS being added at the same time as cells were seeded into the MPs (see Figure 1(b) for an overview).

For $1 \mu \mathrm{M}$ hypericin (Figure 3(a)), a phototoxic effect can be observed for all three protocols as, after illumination with a light fluence of $2.1 \mathrm{~J} \cdot \mathrm{cm}^{-2}$, less than $3 \%$ of cells survived the treatment. When hypericin was added at the time of cell seeding and was incubated together with the cells, the clearest decline in viability is found with less than 5\% surviving cells after illumination with $1.3 \mathrm{~J} \cdot \mathrm{cm}^{-2}$ and a $50 \%$ survival rate (LD50, Table 4 ) at $0.4 \mathrm{~J} \cdot \mathrm{cm}^{-2}$. The phototoxic effect is less pronounced after standard PDT ("Exp. B") but still results in complete eradication of the cell population. An almost linear but smaller decrease of viable cells is found if only plate-adhered hypericin was available, with an LD50 of $1.0 \mathrm{~J} \cdot \mathrm{cm}^{-2}$; although even with this protocol, cells completely deceased after the highest light dose was applied. After the hypericin concentration was increased to $5 \mu \mathrm{M}$ (Figure $3(\mathrm{~b})$ ), the differences between the three tested PDT protocols became almost imperceptible. The LD50 values for all three protocols lie between 0.5 and $0.6 \mathrm{~J} \cdot \mathrm{cm}^{-2}$ with less than $5 \%$ survival at $1.3 \mathrm{~J} \cdot \mathrm{cm}^{-2}$. 


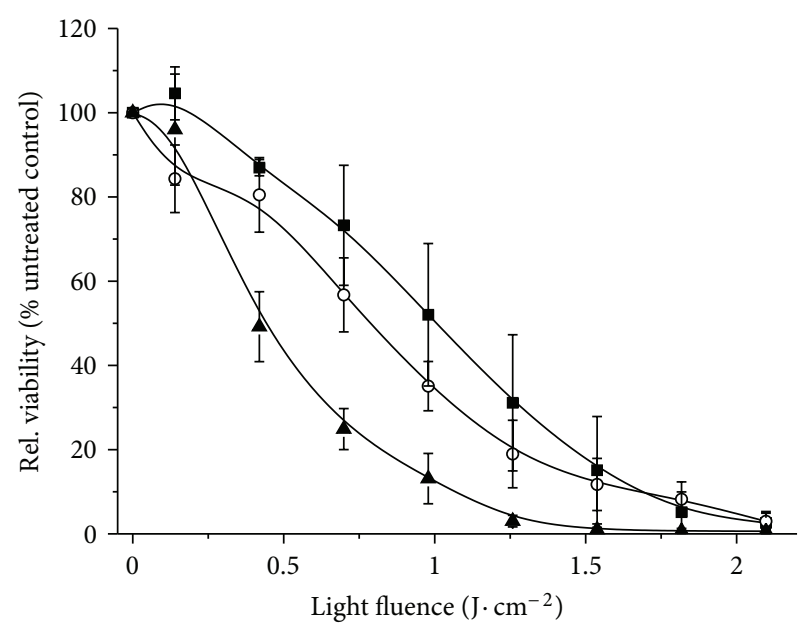

$\rightarrow$ Exp. A: PS preincubation - - Exp. B: seed cells, then PS

(a)

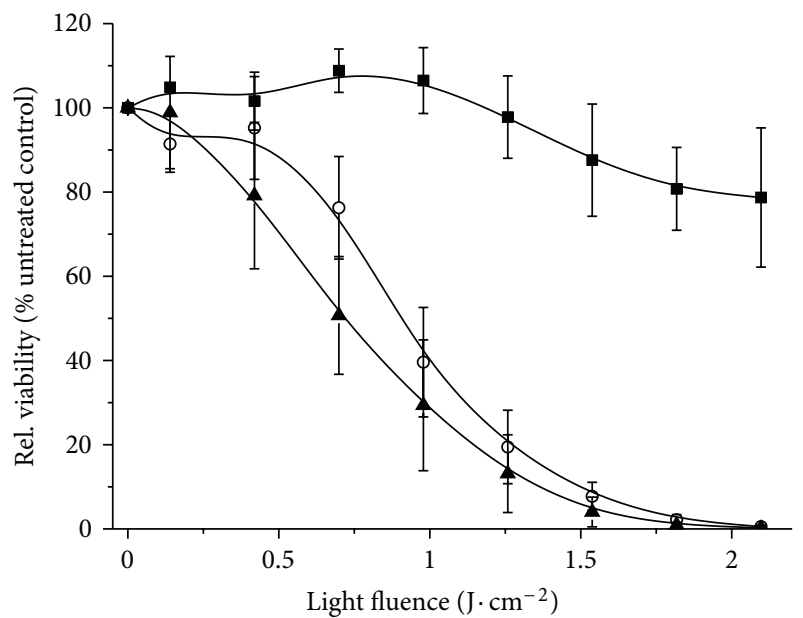

$\rightarrow$ Exp. A: PS preincubation - Exp. B: seed cells, then PS

(c)

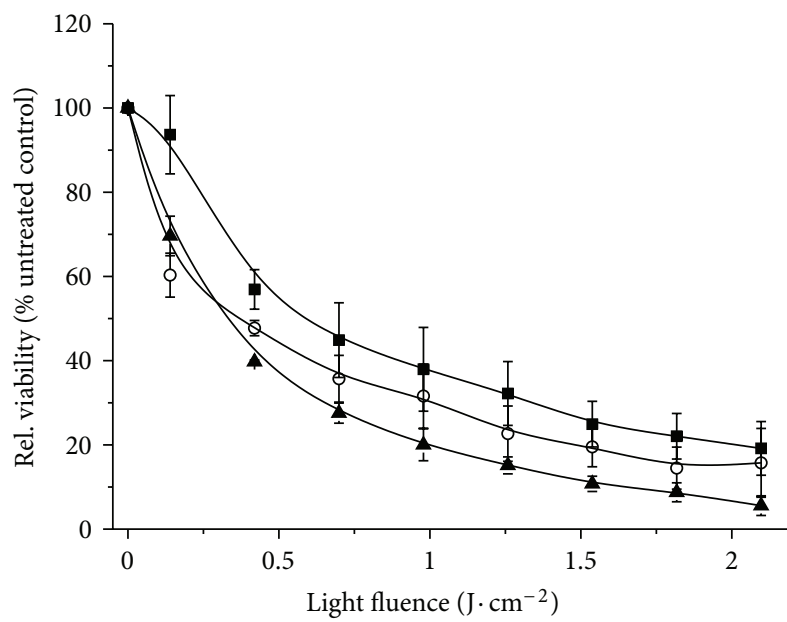

$\rightarrow-$ Exp. A: PS preincubation - Exp. B: seed cells, then PS

(e)

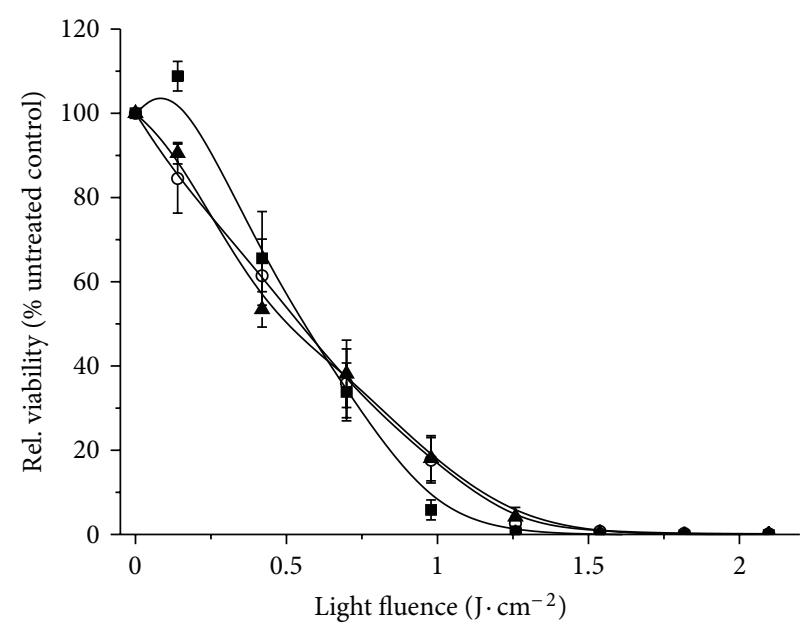

$\rightarrow$ Exp. A: PS preincubation $\rightarrow$ Exp. C: seed cells + PS - Exp. B: seed cells, then PS

(b)

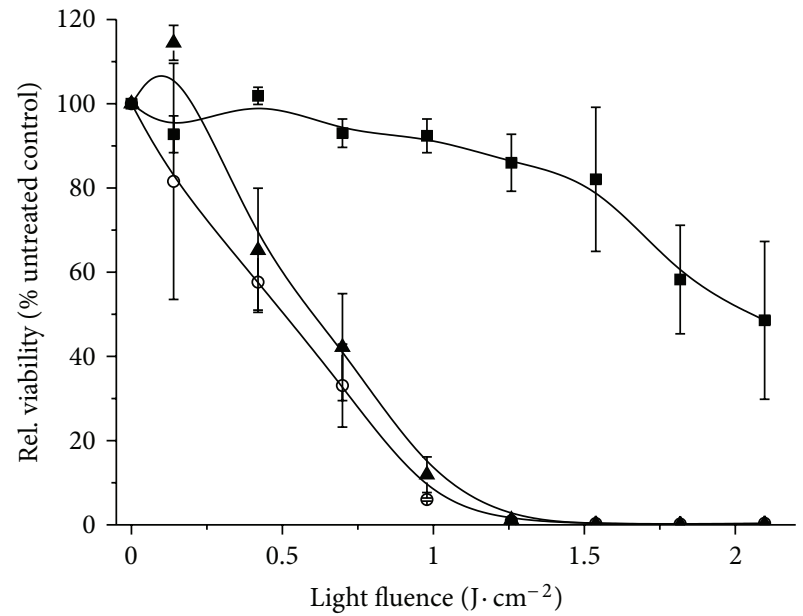

- Exp. A: PS preincubation $\multimap$ Exp. B: seed cells, then PS

(d)

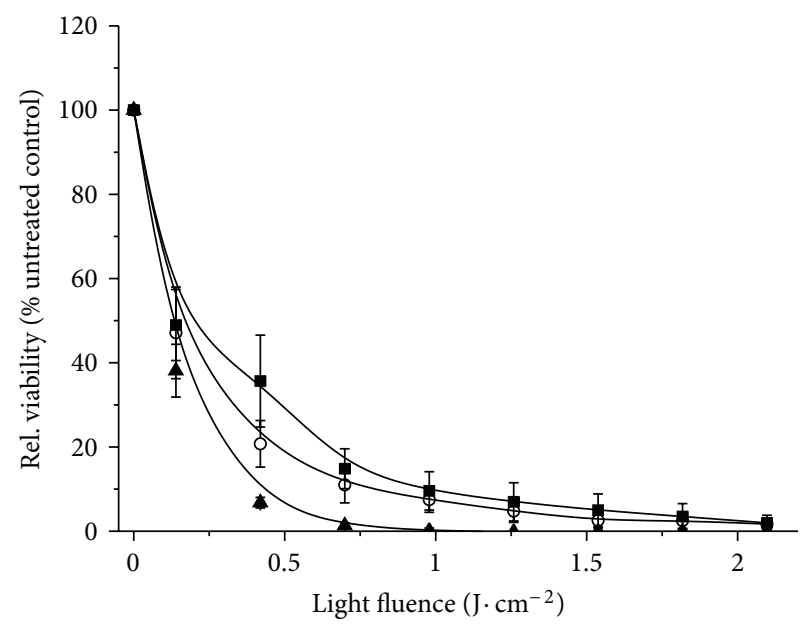

$\rightarrow-$ Exp. A: PS preincubation $\rightarrow-$ Exp. B: seed cells, then PS

$\neg$ Exp. C: seed cells + PS

(f)

Figure 3: Continued. 


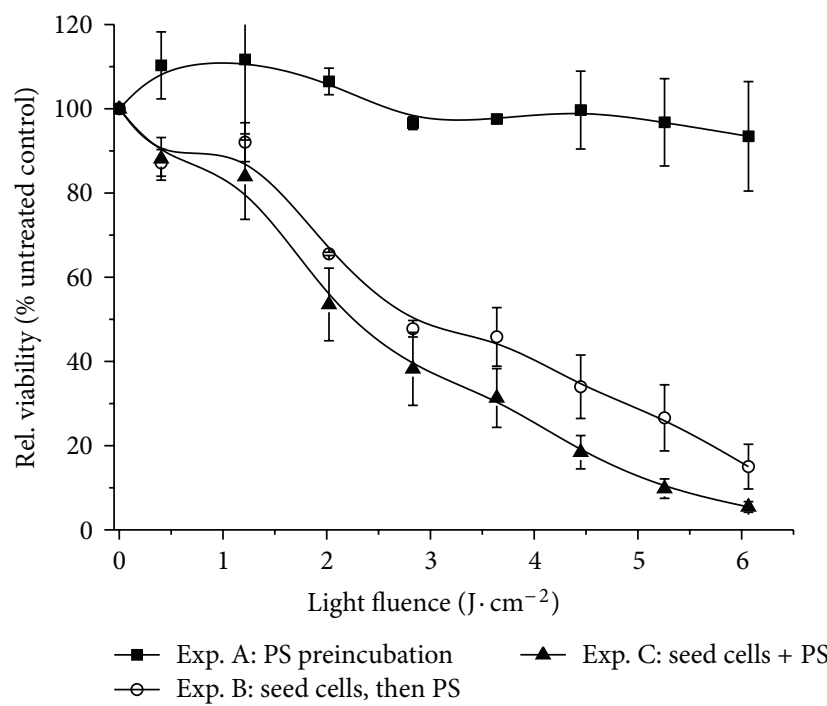

(g)

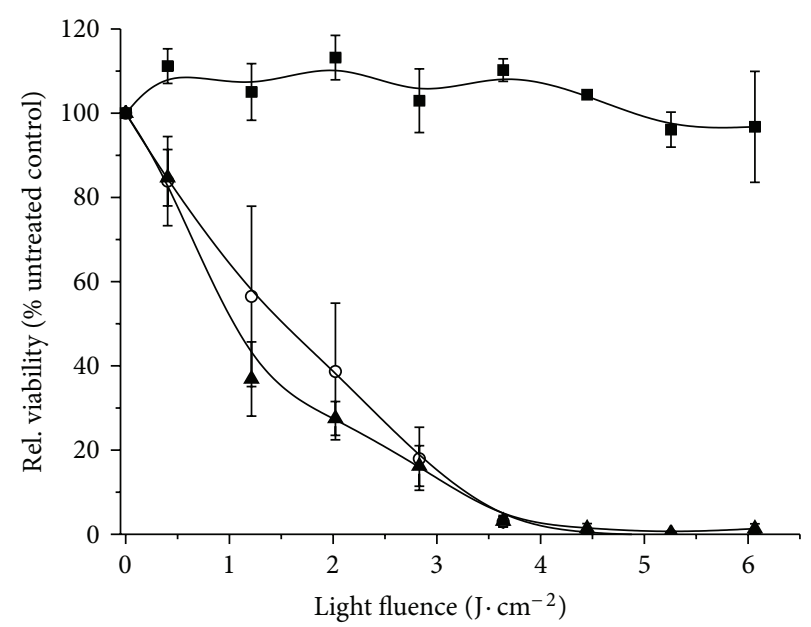

$\rightarrow$ Exp. A: PS preincubation - Exp. B: seed cells, then PS

(h)

FIGURE 3: Phototoxicity of PS adhered to microplates. To determine the phototoxic effect of PS adhered to microplates, three different incubation protocols were applied; PDT protocol A with cells being seeded after plates were preincubated with PSs; the standard PDT protocol $\mathrm{B}$ with cells being seeded prior to PS incubation, and protocol C with cells and PS being added to the plate concurrently. As photosensitizers $1.0 \mu \mathrm{M}$ hypericin (a) or $5.0 \mu \mathrm{M}$ hypericin (b); $1.0 \mu \mathrm{M}$ PVP-hypericin (c) or $5.0 \mu \mathrm{M}$ PVP-hypericin (d); $0.4 \mu \mathrm{M}$ Foscan (e) or $2.0 \mu \mathrm{M}$ Foscan (f) or $10 \mu \mathrm{M} \mathrm{AlPCS}$ (g) and $50 \mu \mathrm{M} \mathrm{AlPCS}_{4}(\mathrm{~h})$ were employed. Cell viability was determined using the resazurin assay $24 \mathrm{~h}$ after illumination; results are shown relative to untreated controls. Abbreviations: Exp.: experiment; PS: photosensitizer.

TABLE 4: Photosensitizing efficiency of tested PDT protocols expressed as LD50.

\begin{tabular}{lcccc}
\hline \multicolumn{1}{c}{ Photosensitizer } & & \multicolumn{3}{c}{ LD50 $\left(\mathrm{J} \cdot \mathrm{cm}^{-2}\right)$} \\
& & Exp. A & Exp. B & Exp. C \\
\multirow{2}{*}{ Hypericin } & $1.0 \mu \mathrm{M}$ & 1.00 & 0.79 & 0.44 \\
& $5.0 \mu \mathrm{M}$ & 0.56 & 0.55 & 0.50 \\
\hline \multirow{2}{*}{ PVP-hypericin } & $1.0 \mu \mathrm{M}$ & n.a. & 0.91 & 0.72 \\
& $5.0 \mu \mathrm{M}$ & 2.06 & 0.51 & 0.60 \\
\hline \multirow{2}{*}{ Foscan } & $0.4 \mu \mathrm{M}$ & 0.59 & 0.37 & 0.33 \\
& $2.0 \mu \mathrm{M}$ & 0.20 & 0.17 & 0.14 \\
\hline \multirow{2}{*}{ AlPCS $_{4}$} & $10 \mu \mathrm{M}$ & n.a. & 2.87 & 2.25 \\
& $50 \mu \mathrm{M}$ & n.a. & 1.52 & 1.05 \\
\hline
\end{tabular}

n.a.: not applicable.

The water-soluble formulation of hypericin, PVPhypericin, shows a completely different behavior in terms of phototoxicity of MP-adhered PS (Figure 3(c)). Both protocols with $1 \mu \mathrm{M}$ PVP-hypericin being directly available for cells due to its addition to the incubation medium are comparable with a distinct phototoxic effect yielding LD50s of $0.9 \mathrm{~J} \cdot \mathrm{cm}^{-2}$ ("Exp. B") and $0.7 \mathrm{~J} \cdot \mathrm{cm}^{-2}$ ("Exp. C"), and without viable cells after illumination with $>1.5 \mathrm{~J} \cdot \mathrm{cm}^{-2}$. In contrast, if PVP-hypericin was preincubated with the plate ("Exp. A"), only a small reduction in cell viability can be found, with $21 \%$ toxicity after maximum illumination. With a higher PVP-hypericin concentration of $5 \mu \mathrm{M}$ (Figure 3(d)), the phototoxic effect is intensified for cells directly incubated with the PS, with a fast decrease of viability for illumination up to $1.3 \mathrm{~J} \cdot \mathrm{cm}^{-2}$ and no viable cells at higher fluences. For indirect PVP-hypericin administration via plate-adhered PS, the viability was similarly reduced to a minimum of $49 \%$ after illumination with $2.1 \mathrm{~J} \cdot \mathrm{cm}^{-2}$.

If Foscan was used as PS, the differences in response to photodynamic treatment between the three applied protocols were least distinct. With the lower concentration of $0.4 \mu \mathrm{M}$ (Figure 3(e)), the strongest phototoxic effect was achieved after simultaneously seeding and incubating the cells with Foscan. Here, we observed a continuous decline of cellular viability down to $5.6 \%$ after maximum illumination. With the standard PDT protocol, the curve progression is comparable but with a less intense effect and a final viability of $15.7 \%$. Illumination of cells in Foscan-preincubated plates shows similarly a strong phototoxic effect, resulting in 19.6\% survival after the highest light dose was applied and, compared to the other tested protocols, the highest LD50 of $0.6 \mathrm{~J} \cdot \mathrm{cm}^{-2}$. The three curves are assimilated when the Foscan concentration was increased to $2 \mu \mathrm{M}$ (Figure $3(\mathrm{f})$ ). Here we found a nearly exponential decrease in cell viability for all protocols with LD50 values between 0.1 and $0.2 \mathrm{~J} \cdot \mathrm{cm}^{-2}$ and less than $5 \%$ surviving cells after illuminating with $1.6 \mathrm{~J} \cdot \mathrm{cm}^{-2}$.

For $10 \mu \mathrm{M} \mathrm{AlPCS}$ (Figure 3(g)), both protocols with directly available PS (B and C) show a comparable, nearly linear decrease of cell viability (although compared to all other PSs employed, the light dose has been increased up to a maximum of $6.1 \mathrm{~J} \cdot \mathrm{cm}^{-2}$ ). For the standard PDT-protocol, the LD50 was $2.9 \mathrm{~J} \cdot \mathrm{cm}^{-2}$ with a minimum of $15.0 \%$ remaining viable cells and an LD50 of $2.3 \mathrm{~J} \cdot \mathrm{cm}^{-2}$ and $5.4 \%$ survivors for protocol C, respectively. In contrast, if the cells were seeded into plates that were preincubated with $\mathrm{AlPCS}_{4}$, there was 


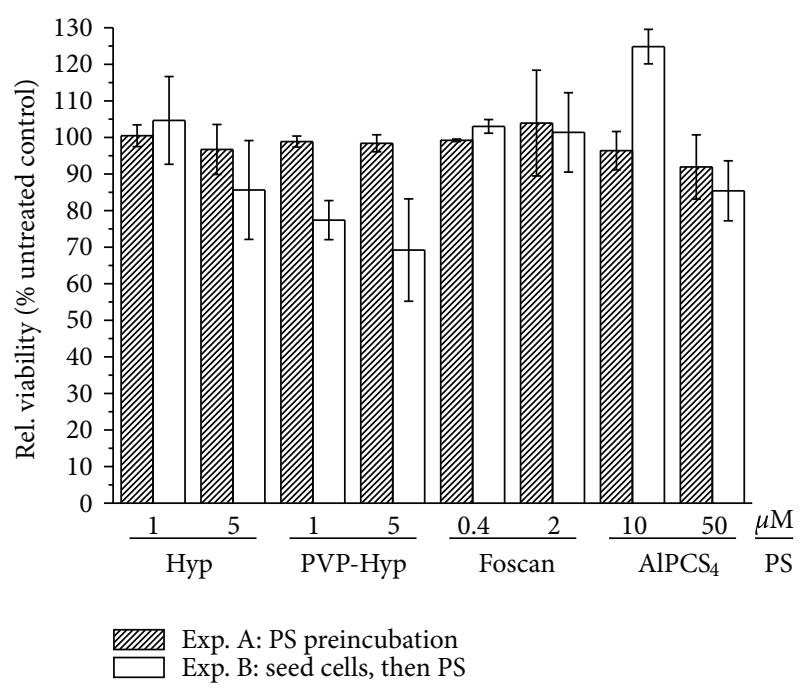

FIgURE 4: Cytotoxicity of PS without illumination. The cytotoxic effect of the four tested PSs in the dark was determined for cells seeded into microplates that were preincubated with PS and for cells that were seeded into microplates before PS was added (standard protocol). Twenty-four hours thereafter, cellular survival was assessed by means of resazurin assay. Results are expressed as ratio relative to untreated control. Abbreviations: exp, experiment; PS, photosensitizer; (PVP-)Hyp, (polyvinylpyrrolidone-)Hypericin.

no phototoxic effect observable. After increasing the AlPCS $_{4}$ concentration to $50 \mu \mathrm{M}$ the cytotoxic effect on cells treated with protocols B and C, that is, with direct access to PS, increased. Cell survival decreases linear, but, now with a more pronounced decline, LD50 values of $1.5 \mathrm{~J} \cdot \mathrm{cm}^{-2}$ (B) and $1.1 \mathrm{~J} \cdot \mathrm{cm}^{-2}(\mathrm{C})$ and almost no viability after illumination with $>3.6 \mathrm{~J} \cdot \mathrm{cm}^{-2}$. Similar to the lower concentration of $\mathrm{AlPCS}_{4}$, for cells in preincubated plates there was no significant effect detectable. Even after maximum illumination still $96.7 \%$ of cells were intact.

\subsection{Cytotoxicity of PS without Illumination (Dark Toxicity).}

To assess the influence of the PS on viability of cells without illumination and possible differences between a standard PDT protocol and the use of PS-coated microplates, we analyzed the dark cytotoxicity.

For all sensitizers and concentrations tested, no dark toxic effect is notable if the cells were added to plates preincubated with the PS (Figure 4). The viability of the cells is in a range between $92 \%$ and $104 \%$ for all PSs. In the standard PDT protocol where preseeded cells were incubated with the PS afterwards, the higher hypericin concentration of $5 \mu \mathrm{M}$ caused a small but negligible increase of dark toxicity, whereas for the lower concentration cells further seem unaffected by the PS. For PVP-hypericin a decline in viability is already visible for the low concentration of $1 \mu \mathrm{M}$ and even more pronounced for $5 \mu \mathrm{M}$ ( $77 \%$ and $69 \%$ viability, respectively) if incubated with the standard protocol.

For Foscan, the differences in the dark toxicity between the two protocols are marginal; similarly, cells directly incubated with the sensitizer do not show decreased viability.
After direct incubation of the cells with $10 \mu \mathrm{M} \mathrm{AlPCS}$ there is a surprising increase in viability of about $25 \%$ compared to the control. In contrast, the high $\mathrm{AlPCS}_{4}$ concentration leads to a small but insignificant decline in survival.

\section{Discussion}

The development of a new PS from its synthesis, physicochemical, and in vitro characterization to clinical use is a multistep process. Especially the initial screening for suitable substances is based on experiments performed with cell cultures. In vitro experiments are commonly used to characterize a PS in terms of phototoxicity, effects of the PS in the dark, the uptake behavior into cells, and also the mechanisms of cell death or pathways and factors leading to successful destruction of the target cells. Basic research is reliant to this cheap and versatile tool. Within the last decades the application of single-use plastic materials has been established, allowing for high throughput analysis of key features of a PS, combined with convenient and safe handling. Experiments performed in microplates offer several convincing advantages such as the possibility of multiparametric experiments under reproducible conditions, saving time, material, and resources and therefore the improvement of the workflow.

In a recent study we have shown several challenges concerning the use of microplates in PDT experiments. In the absence of serum lipophilic PSs adhere to standard cell culture microplates obtained from various manufacturers in a kinetic-like, time-dependent manner. This may lead to misinterpretation of MP-based experiments on cellular PS uptake if proper controls are not included [8].

In the current study we addressed the question whether plate-adhered PS is transferred into cells in plates that were preloaded with PS. For the lipophilic substances hypericin and Foscan we confirm our pervious observation that high amounts of the PS adhere to microplates in the absence of serum. Only very small quantities of the hydrophilic PVPhypericin and $\mathrm{AlPCS}_{4}$ stick to the surfaces of MPs. In all cases we observed that addition of cells decreased the overall content of PS; to a certain extent we suppose that this is caused by loss of cells, and therewith also PS, due to washing or other mechanisms of fluorescence loss, for example, due to PS aggregation.

When we addressed the redistribution of MP-adhered PS after addition of cells, we found that, interestingly, both lipophilic photosensitizers, hypericin and Foscan behave very differently. After addition of cells to MPs preloaded with hypericin, a significant amount of the PS is redistributed and bound to the eukaryotic cells, as shown by separate fluorescence measurements of detached cells: $37 \%-68 \%$ of the MP-adhered hypericin relocalizes into A431 cells after addition. PVP-hypericin shows very similar properties; also, the fluorescing compound has the ability to partially detach and is incorporated into cells. However, due to a much lower adherence of the water-soluble PVP-hypericin when compared to hypericin (we observed a three-times less adherence of PVP-hypericin in average), the absolute amount of PVPhypericin re-localizing to cells is also lower. The comparable 
behavior may be explained by the chemical properties of PVP-hypericin: in this formulation hypericin is not covalently bound to polyvinylpyrrolidone, but forms complexes consisting of two PVP- and one hypericin molecules [13]. As a result, a small amount of hypericin molecules might be able to adhere to the surface and then redistribute similar to pure hypericin. We hypothesize that for both hypericinbased PSs the process of redistribution is driven by the lipophilicity of the photoactive compound. Hypericin favors incorporation in the cells' lipophilic structures, such as the plasma membrane and/or membranes of the endoplasmic reticulum $[16,17]$. Even though the experimental schedule of adding the PS before cells might sound hypothetical, we suggest that preloaded plastic surfaces might represent a reversible depot of hypericin. Although speculative regarding the feasibility and efficiency, plastic material-for example, particles or needles-loaded with the PS directly inserted into tumors might represent a new approach of delivering this photosensitizing substance to the target tissue without the drawback of systemic photosensitization.

Among all PSs in this study, Foscan shows the strongest adherence to cell culture MPs. Only very small fractions of this PS diffuse into cells upon addition to preloaded MPs. However, the overall amount of MP-adhered Foscan is much higher than all other PSs tested in this study (see Table 3). Combined with the excellent phototoxicity of this substance, the relocalized PS might be sufficient to induce cell killing upon illumination. The amounts of $\mathrm{AlPCS}_{4}$ are too small to allow for quantitative analysis of PS redistribution. The fluorescence values are within the experimental error.

The question whether or not the PS adhered to MPs is phototoxic to cells upon illumination is of prime importance for the comparison of cell culture-based experiments performed in plastic compartments to the in vivo situation. Our results clearly demonstrate that both lipophilic PSs are considerably phototoxic if adhered to the surfaces of microplates. At the lower concentrations employed in this study ( $1 \mu \mathrm{M}$ hypericin, $0.4 \mu \mathrm{M}$ Foscan) the cytotoxicity of the PSs preloaded to microplates is only slightly lower when compared to either adding the respective photoactive substance to the cells or seeding out cells in medium with PS. Surprisingly, at 5-fold higher concentrations $(5 \mu \mathrm{M}$ hypericin, $2 \mu \mathrm{M}$ Foscan) the differences among all three experimental procedures are minimized and preloading MPs with either of both substances is comparably phototoxic as the standard PDT procedure. We cannot distinguish whether the PS re-localizing/binding to target cells (see Figure 1) or the photo-activated dye adhered to the MP (or a combination of both) causes the lethal overproduction of reactive oxygen species. However, loading plastic surfaces with PSs such as Foscan could further be contemplated in order to accomplish disinfection of these surfaces from multiresistant bacteria, although the efficacy of this application on prokaryotic cells has not been verified yet.

Preincubation of MPs with either PVP-hypericin or $\mathrm{AlPCS}_{4}$, followed by the addition of A431 cells does not induce a significant phototoxic effect to this model system. Cell death can only be observed in case the PSs are either added after or in combination with seeding of cells. Five $\mu \mathrm{M}$
PVP-hypericin and relatively high light fluences $\left(>2 \mathrm{~J} \cdot \mathrm{cm}^{-2}\right)$ cause $50 \%$ of cells to lose their metabolic activity, which is not the case for $50 \mu \mathrm{M}$ AlPCS$_{4}$. Both substances differ in their hydrophilic character: AlPCS $_{4}$ is hydrophilic per $s e$; PVP-hypericin is made water soluble by the addition of polyvinylpyrrolidone to hypericin [13], resulting in a different behavior at the higher concentrations employed.

Concluding, lipophilic photosensitizers, such as hypericin and Foscan, adhere to the surface of microplates and have the potential to at least partially relocalize into cells. Upon illumination, these dyes induce a phototoxic effect comparable to the standard in vitro PDT procedure. For the hydrophilic molecules PVP-hypericin and $\mathrm{AlPCS}_{4}$, the small amounts of plate-adhered PS are not sufficient to induce cytotoxicity in added cells when photo-activated. We suggest that lipophilic substances should be tested for their adherence to cell culture microplates in order to rule out artifacts and provide better comparability to the in vivo situation. Furthermore, the ability of these plastic materials to reversibly store PS molecules might turn out as worth of examining as a new approach for PS delivery to (bacterial) target cells or (eukaryotic) tissue or for development of antimicrobial coatings of plastic surfaces.

\section{Abbreviations}

A 431: Human epithelial carcinoma cells

$\mathrm{AlPCS}_{4}$ : Aluminum (III) phthalocyanine tetrasulfonate chloride

DMEM: Dulbecco's modified Eagle's medium

DMSO: Dimethyl sulfoxide

DPBS: Dulbecco's phosphate-buffered saline

FBS: $\quad$ Fetal bovine serum; Fos, Foscan

HEPES: 4-(2-Hydroxyethyl)-1-piperazineethanesulfonic acid

MP(s): Microplate(s)

mTHPC: Meso-tetrahydroxyphenyl chlorine

PDI: Photodynamic inactivation of microorganisms

PDT: Photodynamic therapy

PS(s): Photosensitizer(s)

PVP: Polyvinylpyrrolidone

ROS: Reactive oxygen species

SEM: $\quad$ Standard error of mean

w/o: Without.

\section{Conflict of Interests}

The authors declare that there are no conflict of interests.

\section{Authors' Contribution}

V. Ziegler and T. Kiesslich have contributed equally to this study.

\section{Acknowledgments}

The authors are grateful to Planta Natural Products (Vienna, Austria) for providing hypericin. This study was supported by 
the Stiftungs- und Foerderungsgesellschaft of the University Salzburg, Austria. T. Kiesslich was supported by a Grant of the Oesterreichische Krebshilfe Salzburg.

\section{References}

[1] P. Agostinis, K. Berg, K. A. Cengel et al., "Photodynamic therapy of cancer: an update," CA: Cancer Journal for Clinicians, vol. 61, no. 4, pp. 250-281, 2011.

[2] D. Fayter, M. Corbett, M. Heirs, D. Fox, and A. Eastwood, "A systematic review of photodynamic therapy in the treatment of precancerous skin conditions, Barrett's oesophagus and cancers of the biliary tract, brain, head and neck, lung, oesophagus and skin," Health Technology Assessment, vol. 14, no. 37, pp. 1-288, 2010.

[3] C. A. Robertson, D. H. Evans, and H. Abrahamse, "Photodynamic therapy (PDT): a short review on cellular mechanisms and cancer research applications for PDT,' Journal of Photochemistry and Photobiology B, vol. 96, no. 1, pp. 1-8, 2009.

[4] K. Plaetzer, B. Krammer, J. Berlanda, F. Berr, and T. Kiesslich, "Photophysics and photochemistry of photodynamic therapy: fundamental aspects," Lasers in Medical Science, vol. 24, no. 2, pp. 259-268, 2009.

[5] M. R. Hamblin and T. Hasan, "Photodynamic therapy: a new antimicrobial approach to infectious disease?" Photochemical and Photobiological Sciences, vol. 3, no. 5, pp. 436-450, 2004.

[6] T. Maisch, C. Bosl, R. M. Szeimies, B. Love, and C. Abels, "Determination of the antibacterial efficacy of a new porphyrinbased photosensitizer against MRSA ex vivo," Photochemical and Photobiological Sciences, vol. 6, no. 5, pp. 545-551, 2007.

[7] V. Engelhardt, B. Krammer, and K. Plaetzer, "Antibacterial photodynamic therapy using water-soluble formulations of hypericin or MTHPC is effective in inactivation of Staphylococcus aureus," Photochemical and Photobiological Sciences, vol. 9, no. 3, pp. 365-369, 2010.

[8] V. Engelhardt, T. Kiesslich, J. Berlanda, S. Hofbauer, B. Krammer, and K. Plaetzer, "Lipophilic rather than hydrophilic photosensitizers show strong adherence to standard cell culture microplates under cell-free conditions," Journal of Photochemistry and Photobiology B, vol. 103, no. 3, pp. 222-229, 2011.

[9] E. Blake, J. Allen, and A. Curnow, "An in vitro comparison of the effects of the iron-chelating agents, CP94 and dexrazoxane, on protoporphyrin IX accumulation for photodynamic therapy and/or fluorescence guided resection," Photochemistry and Photobiology, vol. 87, no. 6, pp. 1419-1426, 2011.

[10] S. Saggu, H.-I. Hung, G. Quiogue, J. J. Lemasters, and A.L. Nieminen, "Lysosomal signaling enhances mitochondriamediated photodynamic therapy in a431 cancer cells: role of iron," Photochemistry and Photobiology, vol. 88, no. 2, pp. 461-468, 2012.

[11] J. Berlanda, T. Kiesslich, V. Engelhardt, B. Krammer, and K. Plaetzer, "Comparative in vitro study on the characteristics of different photosensitizers employed in PDT," Journal of Photochemistry and Photobiology B, vol. 100, no. 3, pp. 173-180, 2010.

[12] H. Falk, "From the photosensitizer hypericin to the photoreceptor stentorin-the chemistry of phenantroperylene quinones," Angewandte Chemie-International Edition, vol. 38, no. 21, pp. 3117-3136, 1999.

[13] A. Kubin, H. G. Loew, U. Burner, G. Jessner, H. Kolbabek, and F. Wierrani, "How to make hypericin water-soluble," Pharmazie, vol. 63, no. 4, pp. 263-269, 2008.
[14] A. Pieslinger, K. Plaetzer, C. B. Oberdanner et al., "Characterization of a simple and homogeneous irradiation device based on light-emitting diodes: a possible low-cost supplement to conventional light sources for photodynamic treatment," Medical Laser Application, vol. 21, no. 4, pp. 277-283, 2006.

[15] J. O'Brien, I. Wilson, T. Orton, and F. Pognan, "Investigation of the Alamar Blue (resazurin) fluorescent dye for the assessment of mammalian cell cytotoxicity," European Journal of Biochemistry, vol. 267, no. 17, pp. 5421-5426, 2000.

[16] J. Berlanda, T. Kiesslich, C. B. Oberdanner, F. J. Obermair, B. Krammer, and K. Plaetzer, "Characterization of apoptosis induced by photodynamic treatment with hypericin in A431 human epidermoid carcinoma cells," Journal of Environmental Pathology, Toxicology and Oncology, vol. 25, no. 1-2, pp. 173-188, 2006.

[17] T. Kiesslich, B. Krammer, and K. Plaetzer, "Cellular mechanisms and prospective applications of hypericin in photodynamic therapy," Current Medicinal Chemistry, vol. 13, no. 18, pp. 2189-2204, 2006. 

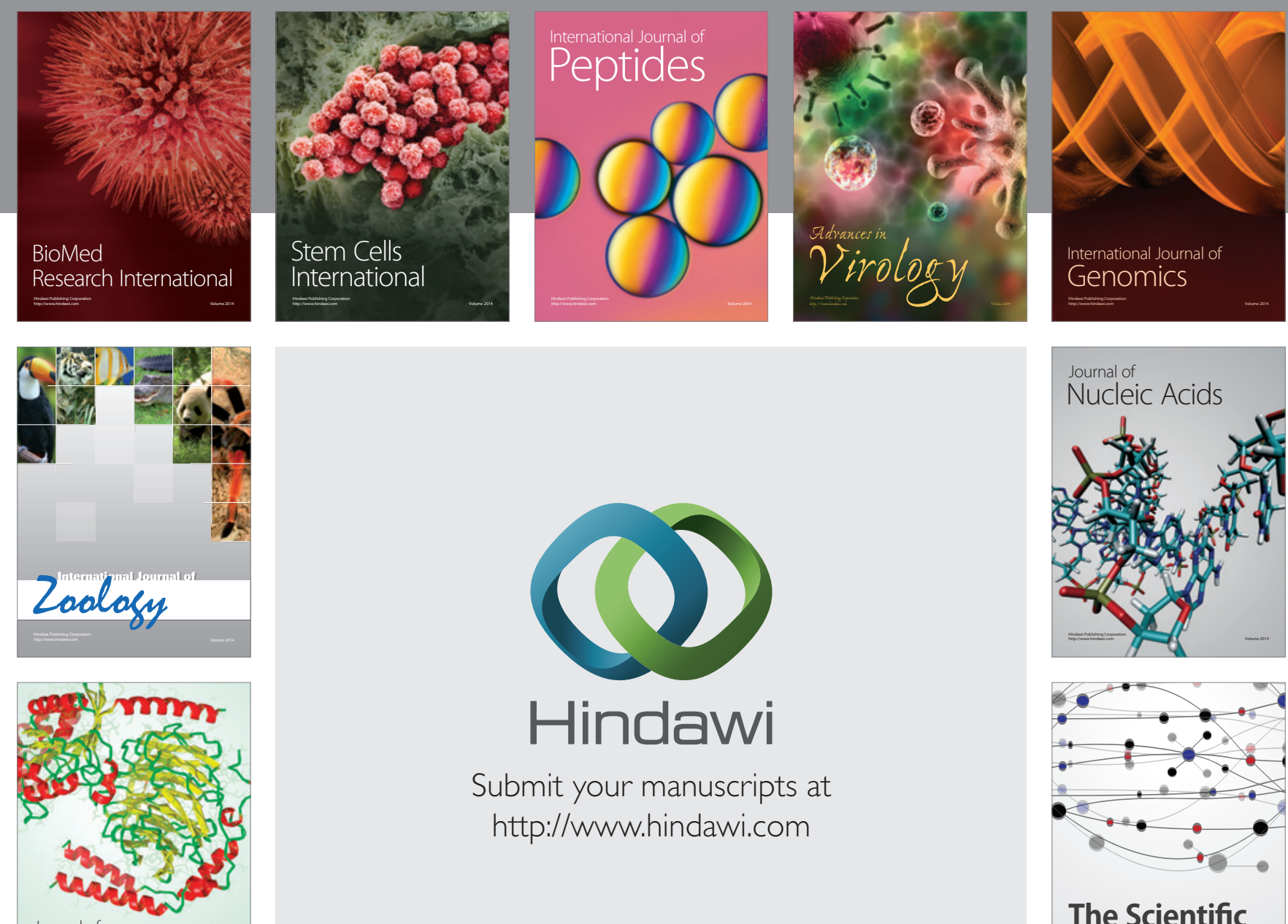

Submit your manuscripts at

http://www.hindawi.com

Journal of
Signal Transduction
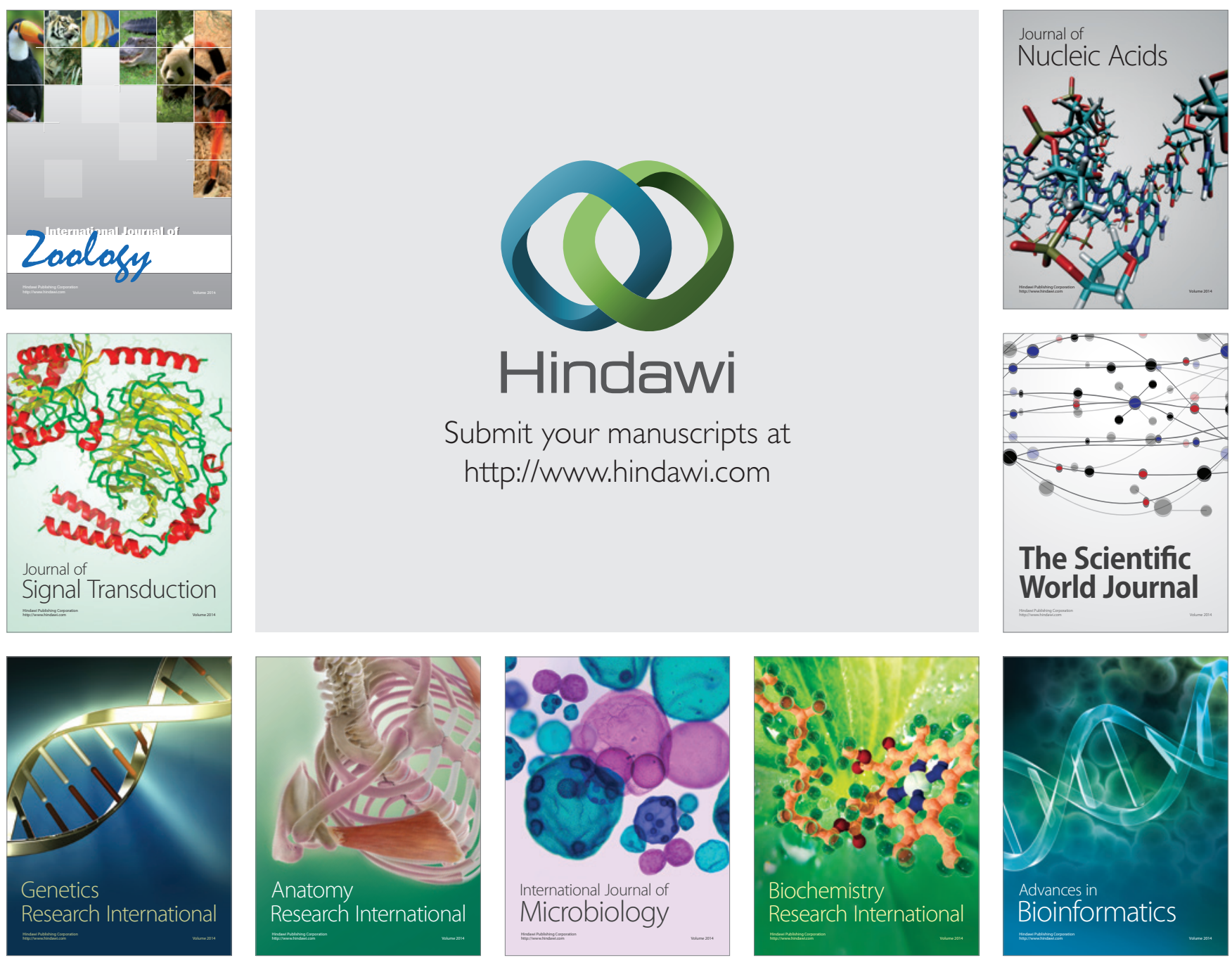

The Scientific World Journal
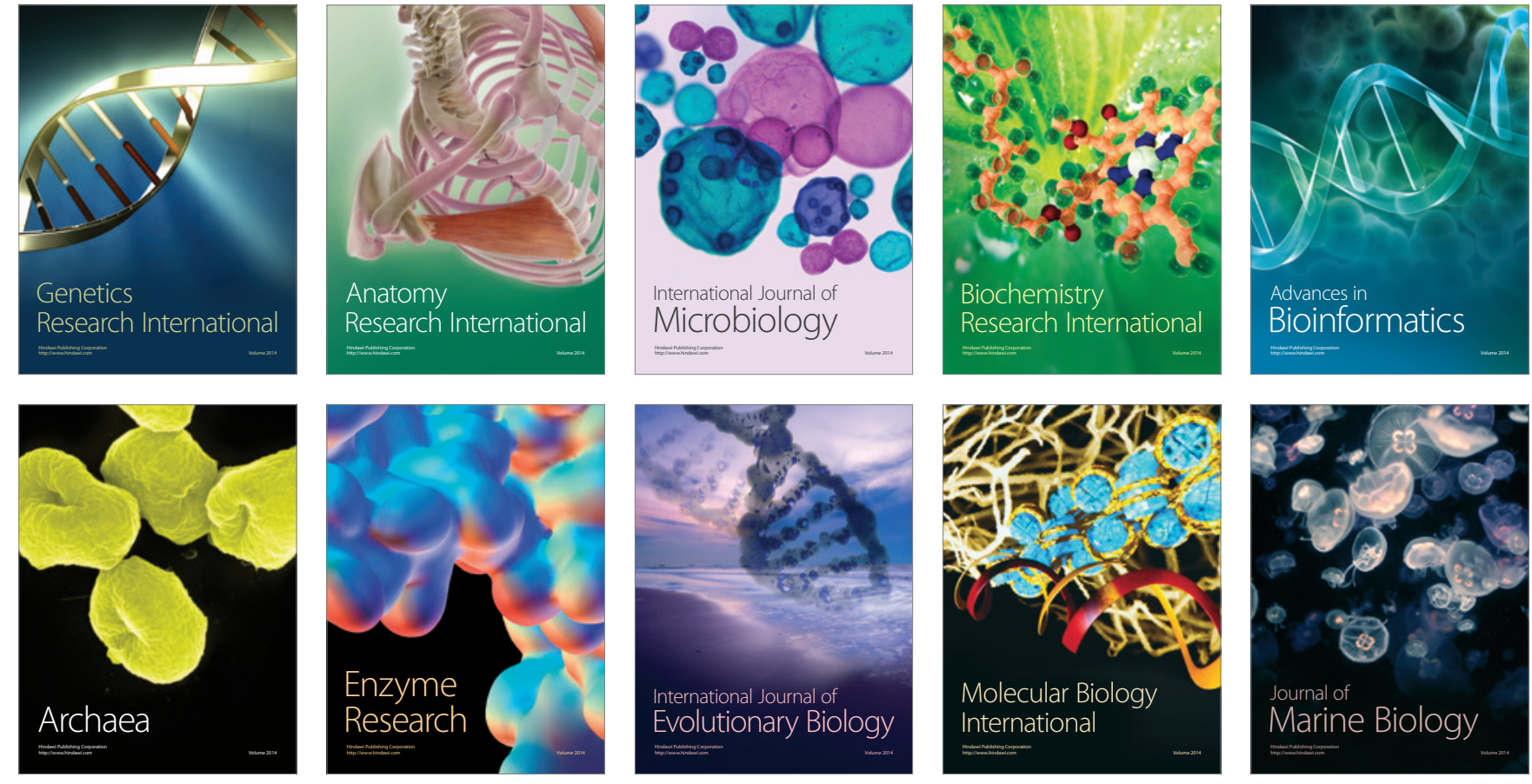